\title{
Hybridization of Tumor Homing and Mitochondria- Targeting Peptide Domains to Design Novel Dual- Imaging Self-Assembled Peptide Nanoparticles for Theranostic Applications
}

\section{Syed Faheem Askari Rizvi}

Lanzhou University

\author{
Azam Ali \\ Lanzhou University \\ Munir Ahmad \\ Institute of Nuclear Medicine and Oncology \\ Shuai Mu \\ Lanzhou University \\ Haixia Zhang ( $\square$ zhanghx@lzu.edu.cn ) \\ Lanzhou University https://orcid.org/0000-0003-0832-6729
}

\section{Short Report}

Keywords: Dual-Targeting Peptides, SPECT/ NIRF Imaging, Mitochondria Targeting Motif, Theranostic agent, Glioblastoma Multiforme

Posted Date: August 11th, 2021

DOI: https://doi.org/10.21203/rs.3.rs-779486/v1

License: (c) (i) This work is licensed under a Creative Commons Attribution 4.0 International License.

Read Full License 


\section{Abstract}

A unique dual-targeting dual-imaging peptide-based nanoprobe was successfully designed by investigating the cyclic heptapeptide having Arg-Gly-Asp-Lys-Leu-Ala-Lys sequence composed of RGD homing motif and KALK mitochondria targeting motif linked via amide bond. The designed peptide was further modified through covalent linkage, characterized and self-assembled to form spherical nanoparticles. The novel Cy5.5-SAPD- ${ }^{99 \mathrm{~m}} \mathrm{Tc}$ nanoparticles were tested in vitro for cytotoxicity, cellular uptake, biocompatibility and apoptosis inducing functionalities. The cellular internalization, enhanced cytotoxicity and selective receptor binding capabilities against U87MG cells, excellent dual-imaging potential, improved apoptosis inducing feature by damaging mitochondria and in vivo preclinical investigations suggested that our newly designed novel dual-targeting dual-imaging nanoparticles may serve as an admirable theranostic probe to treat brain tumor glioblastoma multiforme.

\section{Introduction}

This study describes the development of self-assembled peptide nanoparticles followed by modifications using near-infrared fluorescent dye (Cy $5.5 \mathrm{NHS}$ ) and bifunctional chelating agent radiolabeled with ${ }^{99 \mathrm{~m}} \mathrm{Tc}$ for multimodal imaging and enhanced therapeutic efficacy against brain tumor glioblastoma multiforme.

The development of malignant cells in the circulatory system is progressively assisted by the growth of new blood vessels by utilizing oxygen and nutrients ultimately raising tumor angiogenesis. Selfregulation of angiogenesis causes the progression of diseases like the proliferation of cancer cells, glioblastoma multiforme (GBM), myocardial infarction, and atherosclerosis [1]. For the treatment of cancer, anti-angiogenic therapy in combination with anticancer therapy has been emerging as a novel strategy to combat tumor cell growth by discontinuing their nutrient oxygen supply. MultidomainTargeted drug delivery serves as a guided missile to effectively and efficiently target the cancer cells vasculature. These targeted drugs have been developed using peptides/ proteins, integrin-receptor ligands, antibodies, and aptamers possessed recognition domains and effector domains [2]. There are many cognate receptors and pro-angiogenic factors involve to promote vessel formation in tumors such as fibroblast growth factor-2 (FGF-2), vascular endothelial growth factor (VEGF), and platelet-derived growth factor (PDGF) [3]. These growth factors up-regulate the expression of integrins including $a_{1} \beta_{1}$, $a_{2} \beta_{1}, a_{4} \beta_{1}, a_{5} \beta_{1}, a_{9} \beta_{1}$, and $a_{v} \beta_{3}$-integrins on blood and lymphatic vessels. Several investigations implicate integrins as key regulators of tumor angiogenesis which are also regulating endothelial cell survival, migration and mediate cell-cell adhesion and cell-ECM events [4, 5]. Basic clinical studies reveal that angiogenesis can be blocked by inhibiting the angiogenic signaling pathways, ultimately resulting in tumor dormancy and metastasis [6, 7].

Integrin-mediated signaling pathways play an important role in tissue development and homeostasis, while its deregulation causes multiple brain diseases [8]. Interestingly, integrins are crucial glycoproteins essential for many physiological processes such as proliferation, cell migration, wound healing, 
hemostasis, bone remodeling, and oncogenic transformation $[9,10]$. They are also important for cell-cell and cell-extracellular matrix interactions and comprised of nineteen $\alpha$-and eight $\beta$-subunits $[11,12]$. Among them, $a_{v} \beta_{3^{3}}, a_{v} \beta_{5}, a_{v} \beta_{8^{-}}, a_{5} \beta_{7^{-}}$, and $a_{11 b} \beta_{3^{-}}$integrins have been studied extensively for their active role as an excellent candidate for cancer theranostic [13]. More specifically $a_{v} \beta_{3}$-integrin serves as a receptor for extracellular matrix proteins such as fibronectin, vitronectin, fibrinogen, collagen, laminin, and osteopontin with exposed arginine-glycine-aspartic acid (RGD) sequence [14]. It is expressed on epithelial and mature epithelial cells in low levels, while, highly expressed on the surface of many tumors including carcinomas of breast and lungs, melanomas, osteosarcomas, and glioblastoma [15-17]. Hence, $a_{v} \beta_{3^{-}}$ integrin is considered as a molecular target of interest for the early diagnosis of cancer and selective attachment and internalization of RGD-containing peptides and peptidomimetics for cancer therapy [18]. The cyclic monomeric (RGDfV) and multimeric (Galacto-RGD) peptides have emerged in phase-III clinical trials for diagnosing glioblastoma and in phase-ll trials for many other tumors [19]. It is the first antiangiogenic small molecule drug that specifically targets the $a_{v} \beta_{3^{-}}, a_{v} \beta_{5}$, and $a_{5} \beta_{7}$-integrins and is the first potent and superactive $a_{v} \beta_{3}$-integrin receptor antagonist.

Over the last two decades, both linear and cyclic RGD peptide analogs have been discovered, radiolabeled $\left({ }^{99 \mathrm{~m}} \mathrm{Tc},{ }^{111} \mathrm{In},{ }^{68} \mathrm{Ga}\right.$, and $\left.{ }^{18} \mathrm{~F}\right)$, and evaluated as radiotracers for tumor diagnosis using single-photon emission computed tomography (SPECT) or positron emission tomography (PET) imaging [20]. Linear RGD peptides showed a lack of $a_{v} \beta_{3}$-integrin specificity, low binding affinity, and high enzymatic degradation of the aspartic acid residue due to free rotation around a single bond. On contrary, cyclic RGD peptides were observed to be highly stable towards proteases and increased affinity to $a_{v} \beta_{3}$-integrin receptors and have reduced structural flexibility [21]. Therefore, many researchers have studied the effect of hybrid peptides by incorporating RGD tripeptide with other anticancer peptides analogs including RGD${ }^{111}$ In-DTPA-octreotate [22, 23], ${ }^{18} \mathrm{~F}$-bombesin-RGD [24], ${ }^{99 m}$ Tc-RGD-Bombesin [25], ${ }^{64} \mathrm{Cu}-\mathrm{RGD}_{2}-\mathrm{PG}_{12}{ }^{-}$ bombesin heterodimer [26], 5FU-loaded SF-cRGDfK-Ce6 [27], and RG301-MTX peptide [28] for targeted drug delivery and improved diagnostic as well as therapeutic efficacy.

In the light of above knowledge, we hypothesized that by designing the short head-to-tail cyclic peptide sequence using RGD homing motif ( $a_{v} \beta_{3}$-integrin receptor binding) along with KLAK (mitochondriatargeting) motif without addition of unnecessary long chains of linking amino acids which can improve integrin receptor targeting and mitochondrial damaging potentials for therapeutic applications [29]. Secondly, the modification of this cyclic peptide by incorporation of Near-Infrared fluorescent (NIRF) dye for optical imaging as well as bifunctional chelating agent for radiolabeling with $\beta / \gamma$-emitting radionuclides for SPECT imaging can introduce novel dual-imaging agent for SPECT/ NIRF diagnosis. To the best of our knowledge, we are the first who have designed novel head-to-tail cyclic RGD-KLAK heptapeptide sequence [2]. Further, the effectiveness and efficacy of this newly developed novel NIRF-dye conjugated self-assembled peptide nanoparticles radiolabeled with ${ }^{99 m} \mathrm{Tc}$ (to give Cy5.5@SAPD-99m Tc) was investigated for diagnosis of glioblastoma as well as therapeutic potentials as dual-imaging and dual-targeting probe. The in vitro cell studies as well as in vivo diagnostic and therapeutic studies were 
finally carried out to assess the capabilities of Cy5.5-SAPDN- ${ }^{99 m}$ Tc as SPECT/ NIRF imaging agent for brain tumor glioblastoma multiforme (GBM).

To achieve this goal, firstly, we modified the $₫$-amino group of terminal lysine residue attached to this peptide sequence by coupling with deprotected free $\beta$-carboxylic group of diethylenetriamine pentaacetic acid (DTPA) via covalent linkage as bifunctional chelating agent (BFC). This BFC is useful tool for selective radiolabeling of $y$-emitting radionuclide Technetium-99m (Half-life $6 \mathrm{~h}$; $E r=140 \mathrm{keV}$ ) as SPECT imaging probe. The reaction was successfully accomplished by HATU/DIPEA-chemistry with a satisfactory yield of $\sim 78 \%$ as presented by Step-I in Scheme 1 . The Boc protecting group at the amino group of central lysine residue was removed using 95\% TFA to obtain corresponding free amine preferably available for conjugation with a NIR-fluorescent probe [30]. Secondly, this Peptide-DTPA complex was intrinsically converted to self-assembled nanoparticles via co-assembly of NIRF-probe (Cy5.5 NHS), which covalently conjugated with free amino group of intermediate lysine residue to introduce optical imaging features. A simple and facile synthesis approach was used to design novel dual-targeting self-assembled cyclic peptide-DTPA (SAPD) nanoparticles with high chemical yield and efficacy.

The purity of the cyclic peptide-DTPA (CPD) complex was confirmed by HPLC analysis indicating a single peak with $\geq 98 \%$ purity at retention time $\mathrm{R}_{t}=3.780 \mathrm{~min}$ (Figure $\mathrm{S} 1$ ), HR-MS analysis shows molecular mass peaks for calculated for $\mathrm{C}_{47} \mathrm{H}_{81} \mathrm{~N}_{15} \mathrm{O}_{18}$ with $\mathrm{m} / \mathrm{z}$ found $\left[\mathrm{M}+2 \mathrm{H}^{+}\right]=1144.01$ a.m.u (Figure S2). Furthermore, FTIR-ATR analysis shows superimposed spectrum of cDTPA (black line), cyclic peptide (red line), and cPD complex (blue line) having peaks at $3265.1 \mathrm{~cm}^{-1}$ and $1640.2 \mathrm{~cm}^{-1}$ assigned for stretching vibrations of $-\mathrm{NH}_{2}$ and $-\mathrm{NC}=\mathrm{O}$ group; respectively and peaks at $2109.7 \mathrm{~cm}^{-1}$ designated to bend vibrations of $-\mathrm{COOH}$ group (Figure S3).

To rationalize the generality of self-assembly strategy for CPD complex and optical imaging, we choose Cyanine 5.5 NHS ester as near-infrared fluorescent (NIRF) dye. The cPD complex was successfully selfassembled with Cy5.5 NHS via covalent interactions to form uniform nanoparticles with well-defined spherical shape and "Always ON" NIR-fluorescence property as presented in Step-II (a) of Scheme 1 by using the $\mathrm{pH}$-sensitive method [31,32]. This will facilitates in enhancing the pharmacokinetics and improving the diagnostic as well as therapeutic efficiencies of dual-targeting dual-imaging peptide nanoparticles, whilst maintained intrinsic biocompatibility and biodegradability [33]. The effect of selfassembly on change in fluorescence intensity was assessed by fluorescence spectrophotometer, spectrogram presented in Figure 1a shows peaks at an excitation wavelength of $650 \mathrm{~nm}$ and emission wavelength of $702 \mathrm{~nm}$ in aggregation state, which is nearly consistent with the parent NIRF dye (Cy5.5 $\mathrm{NHS} ; \mathrm{Ex} / \mathrm{Em}=650 / 700 \mathrm{~nm}$ ) with a slight increase in emission wavelength indicating successful coassembly of Cy 5.5 with cPD complex [34]. The freshly synthesized Cy5.5@SAPD nanoparticles were further radiolabeled with Technetium-99m by using fac- $\left[{ }^{99 \mathrm{~m}} \mathrm{Tc}-(\mathrm{CO})_{3}\left(\mathrm{H}_{2} \mathrm{O}\right)_{3}\right]^{+}$core complex for SPECT/ CT imaging. 
The radiosynthon introduced by Alberto et al. has been used widely for preferential labeling of peptides/ proteins to achieve relatively high specificity keeping retained biological property of bioactive molecules [35]. The radiosynthon was successfully prepared with high radiochemical purity of $\geq 97 \%$ showing a single high-intensity peak at retention time $\mathrm{R}_{t}=4.727 \mathrm{~min}$ as indicated by Radio-HPLC analysis (Figure S4). The inset figure shows TLC-SG results depicted that $\mathrm{fac}-\left[{ }^{99 \mathrm{~m}} \mathrm{Tc}(\mathrm{CO})_{3}\left(\mathrm{H}_{2} \mathrm{O}\right)_{3}\right]^{+}$moves

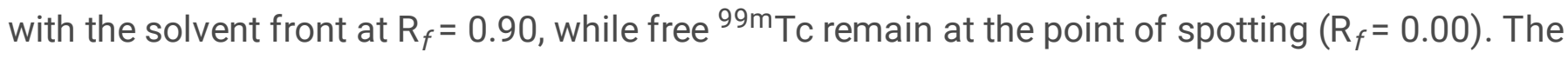
electron donor nitrogen and oxygen groups of DTPA provide an easy platform for radiolabeling with gamma-emitting radionuclides in the presence of suitable reducing agent and optimum $\mathrm{pH}$ value as shown in Step-II (b) of Scheme 1. Consequently, the radiolabelled nanoparticles were observed to remain stable at room temperature over $4 \mathrm{~h}$ incubation period and no change in radiolabeling efficiency was seen by increasing the concentration of Cy5.5@SAPD-99m Tc nanoparticles with a percent radiochemical purity of $>96 \%$ (Figure 1b), obtained using ultracentrifugation technique. The same results were calculated from TLC-SG/ Methanol technique, as inset images presented in Figure S4 shows $~ 97 \%$ yield at $\mathrm{R}_{f}=$ 0.65 , while $<3 \%$ impurities were found in saline [36].

Additionally, Transmission electron microscope (TEM) images presented in Figure 1 (c, d) shows clear spherical morphology of Cy5.5@SAPD and Cy5.5@SAPD-99m Tc nanoparticles; respectively with uniform dispersion in an aqueous medium. The size of Cy5.5@SAPD nanoparticles was observed to be in between $30-40 \mathrm{~nm}$ as indicated in inset Figure 1c' acquired by High resolution-TEM as well as for Cy5.5@SAPD-99m Tc nanoparticles the size reduced to $20-25 \mathrm{~nm}$ as shown by inset Figure $1 \mathrm{~d}$. The clear consecutive bight and dark lattice fringes with interplanar lattice fringe distance of $0.294 \mathrm{~nm}$ as presented in Figure 1d' indicate a tight interface among all three-ingredient which could facilitate balancing the charge on the surface of nanoparticles as well as demonstrates the successful selfassembly of CPD complex with Cy5.5 NHS having crystallinity in novel designed nanoparticles [37]. The dynamic light scattering (DLS) measurements reveal the hydrodynamic size of Cy5.5@SAPD nanoparticles with a diameter of less than $100 \pm 28 \mathrm{~nm}$ as depicted in Figure S5 enabling the capabilities of novel designed nanoparticles in vitro and in vivo [38].

Upon successful modification of dual-targeting cyclic peptide to design dual imaging cyclic peptide nanoparticles, in vitro cancer cell studies were carried out to evaluate the effectiveness, specificity, and efficacy. The dual-targeting capabilities of SAPD nanoparticles were assessed by using $a_{v} \beta_{3}$-integrin positive cancer cell line (U87MG), and $a_{v} \beta_{3}$-integrin negative cells (HEK-293). Both cancer cells were separately treated with Cy5.5@SAPD and Cy5.5@SAPD-99m Tc nanoparticles to estimate the cytotoxicity potential. The results presented in Figure 2a showed that the cytotoxicity effect against U87MG cells was slightly higher for Cy5.5@SAPD-99m Tc nanoparticles as compared to Cy5.5@SAPD nanoparticles, with $\mathrm{EC}_{50}$ values of $20 \mu \mathrm{M}$ and $25 \mu \mathrm{M}$; respectively. On contrary, the MTT assay showed that both nanoprobes were weakly cytotoxic towards HEK-293 cancer cells as $\geq 80 \%$ viable cells were found in 96 well plates as presented in bar graph (Figure 2b). The significantly higher cytotoxicity of Cy5.5@SAPD${ }^{99 m} \mathrm{Tc}$ nanoparticles might be due to the attachment of $\mathrm{y}$-emitting radionuclide compared with 
Cy5.5@SAPD nanoparticles [39]. So, further cell studies were performed using Cy5.5@SAPD nanoparticles to avoid the effect of diagnostic radionuclides.

The CLSM images acquired after treatment with Cy5.5@SAPD nanoparticles showed very less red fluorescence intensity in HEK-293 cells (Figure 2c), alternatively showed bright red fluorescence intensity in U87MG cells (Figure 2d). The co-localization of DAPI staining in the nuclear region shows blue fluorescence, while the merged image showed localization of red fluorescence in the nuclear periphery region. These results highlight the specificity and efficacy of newly designed nanoparticles for $a_{v} \beta_{3}$ integrin positive cancer cells due to RGD tripeptide [11].

Further, we investigated the potential of apoptosis induction in U87MG cancer cells upon treatment with Cy5.5@SAPD nanoparticles. The results presented in Figure 2e showed $95.6 \%$ live cells as control and figure $2 \mathrm{f}$ showed $17.2 \%$ live cells as well as $26.8 \%$ early apoptotic and $52.7 \%$ late apoptotic cells, while only $1.3 \%$ necrotic cells. This study confirms our hypothesis that our proposed nanoparticles have the potential to kill cancer cells by inducing apoptosis in glioblastoma cancer cells due to the presence of the KLA motif [40]. Moreover, to investigate the appropriate cell apoptosis-inducing pathway, we also performed CLSM imaging study by treating the U87MG cancer cells with Cy5.5@SAPD nanoparticles and stained the cells with Mito-Tracker Green as well as Caspase-3 dyes. The CLSM images acquired with Cy5.5 filter after 30 min incubation time showed that Cy5.5@SAPD nanoparticles internalized into cells via pinocytosis and enters into the mitochondria by disrupting the mitochondrial membrane as indicated in Figure 2g, merged images showed well-overlapped fluorescence intensities to give yellowish-green color, scale bar $20 \mu \mathrm{m}$ was set for all images. This ultimately produces reactive oxygen species (ROS) that causes $m t D N A$ damage, whilst, it releases cytochrome $\mathrm{c}$ to promotes the formation of apoptosome, causing activation of Caspase-3 enzyme as showed in Figure $2 \mathrm{~h}$ [41]. The bright green fluorescence is due to activated Caspase-3 which is well-overlapped with red fluorescence as presented in the merged image to give bright yellow fluorescence intensity in nuclear periphery region $[42,43]$. The merged CLSM images with blue colored holes show stained nuclear region (Figure c, d) while blank holes showed unstained nuclear region (Figure $\mathrm{g}, \mathrm{h}$ ) indicates improved specificity of our novel SAPD nanoparticles to selectively target mitochondria and induces cell apoptosis.

Additionally, we also performed a Bio-TEM imaging study using Cy5.5@SAPD nanoparticles treated U87MG cancer cells, the TEM images showed pinocytic internalization of nanoparticles as shown in Figure 2i. The zoom image shows the accumulation of nanoparticles in the inner-layers of the cell membrane (Figure 2j) and targets the mitochondria to induce apoptosis by damaging the mitochondrial membrane as illustrated by HR-TEM image presented in Figure 2k. Bio-TEM images are in agreement with the CLSM study evidenced the induction of cancer cell apoptosis by damaging the mitochondria with high specificity and improved efficacy $[38,44,45]$.

Additionally, we also investigated the dual-imaging potential of Cy5.5@SAPD-99m Tc nanoparticles in brain tumor glioblastoma (using U87MG cells) and human embryonic kidney (HEK-293) tumor-induced $\left(5 \times 10^{7}\right.$ cells/ mice subcutaneously) female Balb/c mice models. Firstly, the nanoparticles with a 
concentration of $20 \mu \mathrm{g} / 200 \mu \mathrm{L}(\sim 74 \mathrm{MBq})$ saline were injected via tail vein, and images were acquired using a dynamic SPECT/CT camera (NM/ CT 670 Pro Discovery) as well as fluorescence imaging camera (IN VIVO FX Pro Carestream). Images presented in figure 3 (a-c) indicates CT, SPECT, and SPECT/ CT images; respectively acquired after 30 min post-injection (p.i) with coronal, sagittal, and transaxial directions show the occurrence of brain tumor glioblastoma and kidney tumor with excellent accumulation of proposed nanoparticles as tumor-to-background contrast showed at the left side of Balb/c mice [46]. The results presented in Figure 3 (d-g) depicted planar SPCET images acquired at 30 min p.i (Figure 3d left), and $2 \mathrm{~h}$ p.i (right) before therapeutic dose treatment, showed high internalization of radiotracer in brain tumor glioblastoma with $4.7 \pm 0.8 \%$ ID/ g as compared to kidney tumor $(2.1 \pm 0.9$ $\%$ ID/g). The results of the planar SPECT imaging study are comparable with that biodistribution study.

After therapeutic dose (30 mg/ kg b.w) treatment within a very short period of nearly one week, Figure $3 f$ clearly shows very less or negligible accumulation of radiotracer at the site of a brain tumor while prominent uptake can be seen at the kidney tumor site, this is because of the binding potential of RGD motif to $a_{v} \beta_{7}$-integrin overexpressed on HEK-293 cells [9]. The sharp decrease in brain tumor size indicates the insightful excellent therapeutic potential of Cy5.5@SAPD-99m Tc nanoparticles for GBM. Moreover, Figure 3e indicates an ex vivo image presenting pharmacokinetic of Cy5.5@SAPD-99mTc nanoparticles before and (figure $3 \mathrm{~g}$ ) after therapeutic dose treatment. The main accumulation of radiotracer was found in the brain, liver, lungs, and kidneys and nonspecific uptake was observed in the heart, stomach, and spleen. Furthermore, the brain tumor-bearing female Balb/c animal models were subjected to fluorescence camera imaging, and results presented in Figure $3 \mathrm{~h}$ shows in vivo as well as Figure $3(\mathrm{i}, \mathrm{j})$ showed ex vivo images after $30 \mathrm{~min}$ and $2 \mathrm{~h} \mathrm{p.i;} \mathrm{respectively.} \mathrm{The} \mathrm{in} \mathrm{vivo} \mathrm{live} \mathrm{imaging} \mathrm{study}$ shows the accumulation of Cy5.5@SAPD nanoparticles at the site of brain glioma tumors. The tumor uptake was observed to be highly prominent than normal brain tissues and other body organs pointed out the efficacy, specificity, and effectiveness of our newly designed novel Cy5.5@SAPD nanoparticles as compared to previously reported nanoparticles [47-50].

In the light of the above-mentioned results, we firstly designed a dual-targeting peptide sequence consisting of RGD motif for targeting $a_{v} \beta_{3}$-integrin and KLAK pro-apoptotic motif for targeting mitochondria and induce cancer cell apoptosis by activation of the Caspase- 3 enzyme. This dualtargeting peptide probe was further modified with diethylenetriamine pentaacetic acid (DTPA) for radiolabeling with $\gamma$-emitting radionuclide and serves as SPECT/ CT imaging agent. Further, the peptideDTPA complex was self-assembled along with NIR-fluorescence dye Cy5.5 NHS to form uniform spherical shaped nanoparticles for molecular optical imaging study as novel dual-imaging probe. Consequently, these novel dual-imaging and dual-targeting self-assembled cyclic peptide nanoparticles were successfully designed to possess improved diagnostic and therapeutic capabilities with enhanced specifically and efficiently for GBM. The in vitro cytotoxicity assay, apoptosis assay, and CLSM imaging studies illustrated that these newly synthesized Cy5.5@SAPD nanoparticles has potential to internalize specifically and efficiently into U87MG brain tumor cells as compared to HEK-293 kidney tumor cells for early diagnosis of GBM. SPECT/ NIRF theranostic studies in tumor-bearing female Balb/c mice models 
shows the excellent potential of our novel designed Cy5.5@SAPD- ${ }^{99 \mathrm{~m}} \mathrm{Tc}$ nanoparticles to diagnose brain tumor more prominently as well as showed remarkable therapeutic effectiveness within one-week treatment. These outcomes suggested that our novel theranostic nanoparticles (Cy5.5@SAPD-99mTc) may serve efficiently, and specifically as potential SPECT/ NIRF nanoprobe for future pre-clinical and clinical studies against brain tumor glioblastoma multiform.

\section{Materials And Methods}

\section{Chemistry: Synthesis of cyclic Peptide-DTPA Complex A simple condensation reaction of DTPA} dianhydride for coupling with cyclic peptide was carried out using the protocol reported by Shi et al. 2011 after fewer modifications [51]. Briefly, DTPA dianhydride (1.5 $\mathrm{mg}, 0.0042 \mathrm{mmol})$ was dissolved in DMF $(50 \mu \mathrm{L})$ and DMSO $(150 \mu \mathrm{L})$. The deprotected free carboxylic group was activated by treating with HATU ( $1.59 \mathrm{mg}, 0.0042 \mathrm{mmol})$ dissolved in DMF $(50 \mu \mathrm{L})$ and stirred for $30 \mathrm{~min}$ at room temperature. Then, the white crystals of cyclic peptide c[RGD(Boc)KLAK] ( $3.65 \mathrm{mg}, 0.0042 \mathrm{mmol}$ ) were dissolved in Milli-Q water $(200 \mu \mathrm{L})$ and were added dropwise over $30 \mathrm{~min}$ in cDTPA mixture and stirred for another $30 \mathrm{~min}$. Later on, the coupling agent DIPEA $(20 \mu \mathrm{L}, 0.115 \mathrm{mmol})$ dissolved in DMSO $(50 \mu \mathrm{L})$ was added to the reaction mixture to make pH $8.5-9.0$, followed by stirring at $900 \mathrm{rpm}$ for an additional $6 \mathrm{~h}$ at room temperature

under $\mathrm{N}_{2}$-purging. Upon completion of the reaction, the Boc protection group was cleaved by treating with $95 \%$ trifluoroacetic acid in water followed by stirring for $2 \mathrm{~h}$ at room temperature. Finally, the mixture was diluted with ultrapure deionized water and $\mathrm{pH} 6.0$ was adjusted using neat TFA. The final product cyclic peptide-DTPA complex (c[RGDKLAK]-DTPA; CPD) was lyophilized to get white crystalline powder (3.68 $\mathrm{mg}, \sim 78 \%$ yield) stored at $-20^{\circ} \mathrm{C}$ until further used. The complex was characterized for qualitative analysis by using a UV-HPLC system equipped with a C-18 column and UV detector $(\lambda=220 \mathrm{~nm})$. The isocratic mobile phase system having solvent $A(0.1 \%$ TFA in acetonitrile; $87.5 \%)$ and solvent $B(0.1 \%$ TFA in water; $12.5 \%$ ) was used with a flow rate of $1 \mathrm{~mL} / \mathrm{min}$. The confirmation of the required product was analyzed by measuring molar mass using LCMS analysis, while the presence of additional functional groups was confirmed by FTIR-ATR analysis for the cPD complex.

\section{Synthesis of Fluorescent Functionalized Self-assembled Peptide-DTPA Nanoparticles A facile self-} assembling strategy was adopted for the synthesis of cyclic peptide nanoparticles as reported in literature [31]. For this purpose, the CPD complex (1 mg, $0.87 \mathrm{mmol})$ was dissolved in $1.8 \mathrm{~mL}$ of Milli-Q water. Additionally, $0.2 \mathrm{~mL}$ of $0.1 \mathrm{M}$ sodium borate solution $\left(\mathrm{Na}_{2} \mathrm{~B}_{4} \mathrm{O}_{7}, \mathrm{pH}\right.$ 8.3) containing equivalent amount of near-infrared (NIR) fluorescent dye Cy5.5-NHS ester $(0.67 \mathrm{mg} / 20 \mu \mathrm{L}$ DMSO) was added dropwise in $\mathrm{CPD}$ solution. The $\mathrm{pH}$ of the mixture was adjusted to $\mathrm{pH} 6$ using neat TFA in a glass vial and the vial was capped air-tight, the solution was stirred at three different speeds till $48 \mathrm{~h}$ (high intensity $12 \mathrm{~h}$, medium $24 \mathrm{~h}$, and low $48 \mathrm{~h}$ ) at $4^{\circ} \mathrm{C}$ temperature in darkness under $\mathrm{N}_{2}$-purging. On the next day, the reaction was quenched by adding acetic acid ( $150 \mu \mathrm{L} ; 5 \%$ in water), and the suspension was centrifuged at $13000 \mathrm{rpm}$ to isolate the fluorescent dye coupled self-assembled cyclic Peptide-DTPA (Cy5.5@SAPD) nanoparticles, followed by washing with deionized (DI) water twice to remove the acidic water. Next, the sonication was applied for $2 \mathrm{~h}$ to get dispersed SAPD nanoparticles in the DI water and characterized by 
a Fluorescence spectrometer, dynamic light scattering (DLS), and transmission electron microscope (TEM).

Radiosynthesis of Cy5.5@SAPD Nanoparticles The intrinsic radiolabeling of fluorescently coupled selfassembled cyclic peptide-DTPA (Cy5.5@SAPD) nanoparticles with a y-emitting radionuclide $\left({ }^{99 \mathrm{~m}} \mathrm{Tc}\right.$ ) was carried out by using sodium borohydride as reducing agent via fac $\left[{ }^{99 \mathrm{~m}} \mathrm{Tc}(\mathrm{CO})_{3}\left(\mathrm{H}_{2} \mathrm{O}\right)_{3}\right]^{+}$precursor as reported previously [36]. Briefly, the complex of $\mathrm{fac}\left[{ }^{99 \mathrm{~m}} \mathrm{Tc}(\mathrm{CO})_{3}\left(\mathrm{H}_{2} \mathrm{O}\right)_{3}\right]^{+}\left({ }^{99 \mathrm{~m}} \mathrm{Tc}\right.$-tricarbonyl) precursor was prepared by taking $4 \mathrm{mg}$ of $\mathrm{Na}_{2} \mathrm{CO}_{3}, 5.5 \mathrm{mg}$ of $\mathrm{NaBH}_{4}$, and $10 \mathrm{mg}$ of $\mathrm{Na} / \mathrm{K}$-tartrate in deionized water $(0.5$ $\mathrm{mL}$ ), vortex for $30 \mathrm{sec}$ followed by purging with $\mathrm{N}_{2}$-gas for $5 \mathrm{~min}$ to remove bubbles in the solution. Then, $\sim 185 \mathrm{MBq}$ of ${ }^{99 \mathrm{~m}} \mathrm{Tc}$ was added to the solution vial and allowed to incubate for $30 \mathrm{~min}$ at $95^{\circ} \mathrm{C}$. After successful complexation, the solution was cooled at room temperature and $\mathrm{pH} 7$ of the complex was adjusted using $0.1 \mathrm{M} \mathrm{HCl}$ solution. The radiochemical purity of the resulting ${ }^{99 \mathrm{~m}} \mathrm{Tc}$-tricarbonyl complex was assessed by using TLC plates coated with silica gel as stationary phase and by using a mixture of Methanol: $\mathrm{HCl}(95: 5 \% \mathrm{v} / \mathrm{v})$ as mobile phase $\left(\mathrm{R}_{f}\right.$ for ${ }^{99 \mathrm{~m}} \mathrm{Tc}$-tricarbonyl $=0.85-0.95 ; \mathrm{R}_{f}$ for Cy5.5@SAPD$\left.{ }^{99 \mathrm{~m}} \mathrm{Tc}(\mathrm{CO})_{3}=0.55-0.75\right)$ as well as radio-HPLC method. Approximately $98 \%$ pure ${ }^{99 \mathrm{~m} T c \text {-tricarbonyl }}$ complex (185 MBq/ $0.5 \mathrm{~mL}$ saline) was filtered through $0.22 \mu \mathrm{m}$ Millipore and added into Eppendorf tubes containing Cy5.5@SAPD nanoparticles (as ligand; $20 \mu \mathrm{g} / 100 \mu \mathrm{L} \mathrm{Na-PBS,} \mathrm{pH} \mathrm{6.5).} \mathrm{The} \mathrm{reaction}$ mixture was allowed to incubate for $20 \mathrm{~min}$ at $55^{\circ} \mathrm{C}$. After successful radiolabeling, the newly developed radiotracer (Cy5.5@SAPD- ${ }^{99 \mathrm{~m}} \mathrm{Tc}(\mathrm{CO})_{3}$ nanoparticles) was cooled at room temperature, and quality control analysis was performed using the TLC-SG method followed by ultra-centrifugation methods.

Tumor Cell Culture Human brain tumor glioblastoma cell line U87MG ( $a_{v} \beta_{3}, a_{v} \beta_{5}$-integrins positive) and human embryonic kidney cell line HEK-293 ( $a_{v} \beta_{1}$-integrin positive) were purchased from Cell Bank of Chinese Academy of Sciences (CBCAS) and cultured in Iscove's Modified Dulbecco's Medium (IMDM) and RMPI-1640, respectively. Both media were supplemented with $10 \% \mathrm{FBS}$ and $1 \%$ antibiotics $(50 \mathrm{U} / \mathrm{mL}$ penicillin and $50 \mathrm{\mu g} / \mathrm{mL}$ streptomycin). The cells were cultured in humidified incubator having $5 \% \mathrm{CO}_{2}$ and $37^{\circ} \mathrm{C}$ temperature.

Cytotoxicity assay In vitro cytotoxicity study of Cy5.5@SAPD and Cy5.5@SAPD-99m Tc(CO) 3 nanoparticles was assessed by MTT assay. The cancerous cells were first cultured with a density of $5 \times 10^{3}$ cells per well in a 96-well plate using respective growth mediums in a $5 \% \mathrm{CO}_{2}$ incubator at $37^{\circ} \mathrm{C}$ for $24 \mathrm{~h}$ before treatment. Nearly $90 \%$ of confluent cells were washed with phosphate buffer saline (PBS; $\mathrm{pH}$ 7.4) twice and added different concentrations $(0-50 \mu \mathrm{M})$ of test samples supplemented with the serumfree medium in six replica columns and incubated for another $24 \mathrm{~h}$. The next day, the samples containing medium were removed, washing twice with pre-heated (at $\left.37^{\circ} \mathrm{C}\right)$ PBS and $10 \mu \mathrm{L}$ MTT solution $(5 \mathrm{mg} / \mathrm{mL}$ in serum-free medium) was added in each well with incubation for further $4 \mathrm{~h}$. After incubation, the medium was decanted completely, cells were dissolved in $200 \mu \mathrm{L}$ DMSO and incubated for a further 10 min. Then, finally, the treated plates were scanned at $490 \mathrm{~nm}$ absorbance using micro-plate reader SPARK $10 \mathrm{M}$ (TECAN, Switzerland). The same data was used to calculate the half-maximal effective 
concentration $\left(\mathrm{EC}_{50}\right)$ values for both tested samples. All experiments were carried out in triplicate to measure plus/minus standard deviation $( \pm \mathrm{SD})$ values.

Confocal Laser Scanning Microscopy (CLSM) The cancer cells were seeded as described above with a density of $1 \times 10^{5}$ cells per well in a 6-well plate containing a $35 \mathrm{~mm}$ (Mat-Tek) glass-bottom cell culture dish and allowed to incubate for 36-48 $\mathrm{h}$ to achieve $90-95 \%$ confluency. The next day, the cells were treated with a $10 \mu \mathrm{M}$ concentration of Cy5.5@SAPD nanoparticles and incubated in a $5 \% \mathrm{CO}_{2}$ incubator at $37^{\circ} \mathrm{C}$. After $30 \mathrm{~min}$ incubation, the cells were washed thrice with ice-cold PBS to halt the internalization of peptide samples. To observe the mitochondria targeting capabilities of newly designed nanoparticles, the cells were further incubated with Mito-Tracker (green; $1 \mu \mathrm{M}$ ) for 20 min and washed thrice with icecold PBS to observe the co-localization of samples with mitochondria. Furthermore, for the nuclei staining study, the same cells were treated with Hoechst-33258 and incubated for another 20 min followed by washing thrice with PBS. Next, the activity of Caspase-3 was assessed using a Caspase-3 activity staining kit (Solarbio ${ }^{\circledR}$ Co., Ltd. Beijing, China). The cells were stained with a $5 \mu \mathrm{M}$ Casp-3 kit (AcDEVD-pNA) for another 30 min, washed twice with ice-cold PBS. This assay is based on the detection of chromophore $p$-nitroanilide $(p N A)$. All the cells were imaged with a confocal laser scanning microscope $(C L S M)$. All experiments were repeated in triplicate $(n=3)$.

Cells apoptosis/ necrosis assay The apoptosis-inducing potential of Cy5.5@SAPD nanoparticles against U87MG cells was further investigated by fluorescence-activated cell sorting (FACS) technique using fluorescein-annexin V (V-FITC) and propidium iodide (PI) double staining after treatment with newly synthesized nanoparticles. Briefly, the cells were seeded as described above and treated with a $20 \mu \mathrm{M}$ concentration of Cy5.5@SAPD for $24 \mathrm{~h}$. Further, the cells were trypsinized using 0.05\% Trypsin-EDTA and collected by centrifugation at $2000 \mathrm{rpm}$ for $5 \mathrm{~min}$. The supernatant was decanted, cells were washed and resuspended in $100 \mu \mathrm{L}$ PBS. Finally, cells were stained with annexin V-FITC/ PI as per protocol and incubated for $20 \mathrm{~min}$ in dark at room temperature before FACS analysis. The percentage of apoptotic and necrotic cells were calculated by BD FACSCanto ${ }^{\mathrm{TM}}$ flow cytometer (USA) interconnected with FACSDiva version 6.1.2.

Bio-TEM Imaging To observe the mitochondrial-targeting effect of newly designed nanoparticles, U87MG cells were treated with Cy5.5@SAPD nanoparticles overnight. The next day, the cells were washed with PBS three times to remove excess nanoparticles and fixed with $2.5 \%$ glutaraldehyde in $1 \mathrm{~mL}$ of $0.1 \mathrm{M}$ PBS solution at $4^{\circ} \mathrm{C}$ for $24 \mathrm{~h}$. Later on, the cells were trypsinized, collected the pellet, dehydrated with graded ethanol, embedded in epoxy resin, and sliced using a glass knife with a thickness of $40-60 \mathrm{~nm}$. Finally, the cell sections were stained using $5 \%$ uranyl acetate followed by $2 \%$ lead acetate for 20 min and observed in TECAN Bio-TEM.

In vivo Imaging, Pharmacokinetics and Therapeutic Study For in vivo therapeutic study, female Balb/c mice (5 weeks old, 16 - 18 g, 20 mice in total) were purchased from the National Institute of Health (NIH), Islamabad, Pakistan. All animal studies were carried out as per guidelines issued by the animal ethical committee of the National Institute of Health and National Regulation of China for Care and Use of 
Laboratory Animals (Lanzhou University, Gansu, China). Each mice model bearing glioblastoma and human embryonic kidney cancers was successfully established by injecting $5 \times 10^{7}$ cells suspended in $100 \mu \mathrm{L}$ PBS ( $\mathrm{pH}$ 7.4) subcutaneously into the right flank area of each mice and when tumor volume reaches $50-60 \mathrm{~mm}^{3}$ diameter. All mice were divided into two groups ( $\mathrm{n}=3$ each group) randomly to receive normal saline (control), and Cy5.5@SAPD (treated). To observe the in vivo tumor accumulation and therapeutic potential, a single therapeutic dose of Cy5.5@SAPD in saline (30 mg/ kg body weight; b.w) was injected intravenously via the tail vein of each group. The body weight and tumor size of each mouse were monitored after a couple of days. On the sixth day of post-injection, mice were injected with $20 \mu \mathrm{g} / 200 \mu \mathrm{L}$ of Cy5.5@SAPDN-99m $\mathrm{Tc}(\mathrm{CO})_{3}$, and images were acquired using SPECT camera. Later on, they were sacrificed after giving chloroform anesthesia, tumor mass, as well as other organs, were segregated, weighed and radioactivity was measured using $\mathrm{Nal}(\mathrm{TI}) \mathrm{y}$-scintillation counter. At the same time, the images were also acquired using IN VIVO FX camera for optical imaging and segregated organs were also observed for uptake of our newly designed nanoparticles by observing the fluorescence intensity in each organ.

Statistical Analysis All experiments reported in this study were performed in triplicate and results are given as $+/$ - standard deviation ( \pm SD) of ' $n$ ' independent measurements. Statistical significance was calculated using the student's t-test. The significance level was assigned as $p<0.05$.

\section{Declarations}

Supplementary Information The online version contains supplementary material available at

Acknowledgements The authors are cordially thankful to the Director INMOL, Lahore-Pakistan for providing Hot-Lab facilities and access to SPECT/CT camera for animal studies.

Author contribution S.F.A.R.: Conceptualization, Methodology, Validation, Investigation, Writing - Original Draft. A.A.: Formal analysis, Visualization. M.A.: Resources, Project administration. S.M.: Validation, Visualization. H.Z.: Validation, Writing - Review \& Editing, Supervision.

Funding The authors are thankful to National Natural Science Foundation as this research work was financially supported by the National Natural Science Foundation of China (No. 21575055).

Ethical Approval All animal studies performed in this study were in accordance with the compliance of animal ethical committee of the National Institute of Health and National Regulation of China for Care and Use of Laboratory Animals (Lanzhou University, Gansu, China).

Consent to participate Informed consent was obtained from the human participants of this study.

Consent for publication Consent for publication was obtained from the participants.

Conflict of Interest All authors declare no potential conflict of interest in any way. 


\section{References}

1. Shi H, Kwok RTK, Liu J, Xing B, Tang BZ, Liu B. Real-Time Monitoring of Cell Apoptosis and Drug Screening Using Fluorescent Light-Up Probe with Aggregation-Induced Emission Characteristics. Journal of the American Chemical Society. 2012; 134: 17972-17981. 10.1021/ja3064588

2. Rizvi SFA, Mu S, Wang Y, Li S, Zhang H. Fluorescent RGD-based pro-apoptotic peptide conjugates as mitochondria-targeting probes for enhanced anticancer activities. Biomedicine \& Pharmacotherapy. 2020; 127: 110179-110189. https://doi.org/10.1016/j.biopha.2020.110179

3. Lugano R, Ramachandran M, Dimberg A. Tumor angiogenesis: causes, consequences, challenges and opportunities. Cellular and Molecular Life Sciences. 2020; 77: 1745-1770. 10.1007/s00018-01903351-7

4. Avraamides CJ, Garmy-Susini B, Varner JA. Integrins in angiogenesis and lymphangiogenesis. Nature reviews. Cancer. 2008; 8: 604-617. 10.1038/nrc2353

5. Hirakawa S, Kodama S, Kunstfeld R, Kajiya K, Brown LF, Detmar M. VEGF-A induces tumor and sentinel lymph node lymphangiogenesis and promotes lymphatic metastasis. J Exp Med. 2005; 201: 1089-1099. 10.1084/jem.20041896

6. Lin EY, Pollard JW. Tumor-associated macrophages press the angiogenic switch in breast cancer. Cancer Res. 2007; 67: 5064-5066. 10.1158/0008-5472.can-07-0912

7. Ferrara N, Kerbel RS. Angiogenesis as a therapeutic target. Nature. 2005; 438: 967-974. 10.1038/nature04483

8. Ellert-Miklaszewska A, Poleszak K, Pasierbinska M, Kaminska B. Integrin Signaling in Glioma Pathogenesis: From Biology to Therapy. International journal of molecular sciences. 2020; 21: 888906. 10.3390/ijms21030888

9. Schnittert J, Bansal R, Storm G, Prakash J. Integrins in wound healing, fibrosis and tumor stroma: High potential targets for therapeutics and drug delivery. Advanced Drug Delivery Reviews. 2018; 129: 37-53. https://doi.org/10.1016/j.addr.2018.01.020

10. Ganguly KK, Pal S, Moulik S, Chatterjee A. Integrins and metastasis. Cell adhesion \& migration. 2013; 7: 251-261. 10.4161/cam.23840

11. Danhier F, Le Breton A, Préat V. RGD-Based Strategies To Target Alpha(v) Beta(3) Integrin in Cancer Therapy and Diagnosis. Molecular Pharmaceutics. 2012; 9: 2961-2973. 10.1021/mp3002733

12. Zheng Y, Ji S, Czerwinski A, Valenzuela F, Pennington M, Liu S. FITC-Conjugated Cyclic RGD Peptides as Fluorescent Probes for Staining Integrin av $\beta 3 / a v \beta 5$ in Tumor Tissues. Bioconjugate Chemistry. 2014; 25: 1925-1941. 10.1021/bc500452y

13. Sheldrake HM, Patterson LH. Strategies to inhibit tumor associated integrin receptors: rationale for dual and multi-antagonists. J Med Chem. 2014; 57: 6301-6315. 10.1021/jm5000547

14. Park EJ, Myint PK, Ito A, Appiah MG, Darkwah S, Kawamoto E, Shimaoka M. Integrin-Ligand Interactions in Inflammation, Cancer, and Metabolic Disease: Insights Into the Multifaceted Roles of 
an Emerging Ligand Irisin. Frontiers in Cell and Developmental Biology. 2020; 8: 1-17.

$10.3389 /$ fcell. 2020.588066

15. Yeung KY, Dickinson A, Donoghue JF, Polekhina G, White SJ, Grammatopoulos DK, McKenzie M, Johns TG, St John JC. The identification of mitochondrial DNA variants in glioblastoma multiforme. Acta Neuropathol Commun. 2014; 2: 1-21. 10.1186/2051-5960-2-1

16. Malric L, Monferran S, Gilhodes J, Boyrie S, Dahan P, Skuli N, Sesen J, Filleron T, Kowalski-Chauvel A, Cohen-Jonathan Moyal E, Toulas C, Lemarié A. Interest of integrins targeting in glioblastoma according to tumor heterogeneity and cancer stem cell paradigm: an update. Oncotarget. 2017; 8 : 86947-86968. 10.18632/oncotarget.20372

17. Wan J, Guo AA, Chowdhury I, Guo S, Hibbert J, Wang G, Liu M. TRPM7 Induces Mechanistic Target of Rap1b Through the Downregulation of miR-28-5p in Glioma Proliferation and Invasion. Frontiers in oncology. 2019; 9: 1413-1425. 10.3389/fonc.2019.01413

18. Mas-Moruno $\mathrm{C}$, Rechenmacher $\mathrm{F}$, Kessler $\mathrm{H}$. Cilengitide: the first anti-angiogenic small molecule drug candidate design, synthesis and clinical evaluation. Anticancer Agents Med Chem. 2010; 10: 753768. $10.2174 / 187152010794728639$

19. Jamous M, Haberkorn U, Mier W. Synthesis of peptide radiopharmaceuticals for the therapy and diagnosis of tumor diseases. Molecules (Basel, Switzerland). 2013; 18: 3379-3409. $10.3390 /$ molecules 18033379

20. Ji S, Czerwinski A, Zhou Y, Shao G, Valenzuela F, Sowiński P, Chauhan S, Pennington M, Liu S. 99mTc-Galacto-RGD2: A Novel 99mTc-Labeled Cyclic RGD Peptide Dimer Useful for Tumor Imaging. Molecular Pharmaceutics. 2013; 10: 3304-3314. 10.1021/mp400085d

21. Tornesello AL, Buonaguro L, Tornesello ML, Buonaguro FM. New Insights in the Design of Bioactive Peptides and Chelating Agents for Imaging and Therapy in Oncology. Molecules. 2017; 22: 12821303. 10.3390/molecules22081282

22. Capello A, Krenning EP, Bernard BF, Breeman WA, van Hagen MP, de Jong M. Increased cell death after therapy with an Arg-Gly-Asp-linked somatostatin analog. J Nucl Med. 2004; 45: 1716-1720.

23. Hofland LJ, Capello A, Krenning EP, de Jong M, van Hagen MP. Induction of apoptosis with hybrids of Arg-Gly-Asp molecules and peptides and antimitotic effects of hybrids of cytostatic drugs and peptides. J Nucl Med. 2005; 46 Suppl 1: 191S-198S.

24. Yan Y, Chen K, Yang M, Sun X, Liu S, Chen X. A new 18F-labeled BBN-RGD peptide heterodimer with a symmetric linker for prostate cancer imaging. Amino Acids. 2011; 41: 439-447. 10.1007/s00726-0100762-5

25. Liu Z, Huang J, Dong C, Cui L, Jin X, Jia B, Zhu Z, Li F, Wang F. 99mTc-Labeled RGD-BBN Peptide for Small-Animal SPECT/CT of Lung Carcinoma. Molecular Pharmaceutics. 2012; 9: 1409-1417. $10.1021 / \mathrm{mp} 200661 \mathrm{t}$

26. Lucente E, Liu H, Liu Y, Hu X, Lacivita E, Leopoldo M, Cheng Z. Novel 64Cu Labeled RGD2-BBN Heterotrimers for PET Imaging of Prostate Cancer. Bioconjugate Chemistry. 2018; 29: 1595-1604. 10.1021/acs.bioconjchem.8b00113 
27. Mao B, Liu C, Zheng W, Li X, Ge R, Shen H, Guo X, Lian Q, Shen X, Li C. Cyclic cRGDfk peptide and Chlorin e6 functionalized silk fibroin nanoparticles for targeted drug delivery and photodynamic therapy. Biomaterials. 2018; 161: 306-320. 10.1016/j.biomaterials.2018.01.045

28. Goyal R, Jerath G, Chandrasekharan A, Christian Y, Kumar TRS, Ramakrishnan V. Molecular hybridization combining tumor homing and penetrating peptide domains for cellular targeting. Drug Deliv Transl Res. 2021. 10.1007/s13346-021-01035-z

29. Liu Z, Niu G, Wang F, Chen X. 68Ga-labeled NOTA-RGD-BBN peptide for dual integrin and GRPRtargeted tumor imaging. European Journal of Nuclear Medicine and Molecular Imaging. 2009; 36: 1483-1494. 10.1007/s00259-009-1123-z

30. Nie Z, Luo N, Liu J, Zeng X, Zhang Y, Su D. Multi-mode biodegradable tumour-microenvironment sensitive nanoparticles for targeted breast cancer imaging. Nanoscale research letters. 2020; 15: 8194. 10.1186/s11671-020-03309-w

31. Katyal P, Meleties M, Montclare JK. Self-Assembled Protein- and Peptide-Based Nanomaterials. ACS Biomaterials Science \& Engineering. 2019; 5: 4132-4147. 10.1021/acsbiomaterials.9b00408

32. Sun L, Fan Z, Wang Y, Huang Y, Schmidt M, Zhang M. Tunable synthesis of self-assembled cyclic peptide nanotubes and nanoparticles. Soft Matter. 2015; 11: 3822-3832. 10.1039/c5sm00533g

33. Chen Q, Wang X, Wang C, Feng L, Li Y, Liu Z. Drug-Induced Self-Assembly of Modified Albumins as Nano-theranostics for Tumor-Targeted Combination Therapy. ACS Nano. 2015; 9: 5223-5233. $10.1021 /$ acsnano.5b00640

34. Cheng Z, Wu Y, Xiong Z, Gambhir SS, Chen X. Near-Infrared Fluorescent RGD Peptides for Optical Imaging of Integrin avß3 Expression in Living Mice. Bioconjugate Chemistry. 2005; 16: 1433-1441. $10.1021 /$ bc0501698

35. Alberto R, Schibli R, Egli A, Schubiger AP, Abram U, Kaden TA. A Novel Organometallic Aqua Complex of Technetium for the Labeling of Biomolecules: Synthesis of [99mTc(OH2)3(CO)3]+ from [99mTc04]- in Aqueous Solution and Its Reaction with a Bifunctional Ligand. Journal of the American Chemical Society. 1998; 120: 7987-7988. 10.1021/ja980745t

36. Gaonkar RH, Baishya R, Paul B, Dewanjee S, Ganguly S, Debnath MC, Ganguly S. Development of a peptide-based bifunctional chelator conjugated to a cytotoxic drug for the treatment of melanotic melanoma. MedChemComm. 2018; 9: 812-826. 10.1039/c7md00638a

37. Song C, Wang Y, Rosi NL. Peptide-Directed Synthesis and Assembly of Hollow Spherical CoPt Nanoparticle Superstructures. Angewandte Chemie International Edition. 2013; 52: 3993-3995. https://doi.org/10.1002/anie.201209910

38. Yang P-P, Zhang K, He P-P, Fan Y, Gao XJ, Gao X, Chen Z-M, Hou D-Y, Li Y, Yi Y, Cheng D-B, Zhang J-P, Shi L, Zhang $X-Z$, Wang L, Wang $H$. A biomimetic platelet based on assembling peptides initiates artificial coagulation. Science Advances. 2020; 6: 1-12. 10.1126/sciadv.aaz4107

39. Askari Rizvi SF, Zhang H. Emerging trends of receptor-mediated tumor targeting peptides: A review with perspective from molecular imaging modalities. European Journal of Medicinal Chemistry. 2021; 221: 1-22. https://doi.org/10.1016/j.ejmech.2021.113538 
40. Dufort S, Sancey L, Hurbin A, Foillard S, Boturyn D, Dumy P, Coll J-L. Targeted delivery of a proapoptotic peptide to tumors in vivo. Journal of drug targeting. $2011 ; 19: 582-588$.

$10.3109 / 1061186 \times .2010 .542245$

41. Lopez J, Tait SWG. Mitochondrial apoptosis: killing cancer using the enemy within. British Journal of Cancer. 2015; 112: 957-962. 10.1038/bjc.2015.85

42. Gao P, Pan W, Li N, Tang B. Fluorescent probes for organelle-targeted bioactive species imaging. Chemical Science. 2019; 10: 6035-6071. 10.1039/c9sc01652j

43. Zhang X, Sun Q, Huang Z, Huang L, Xiao Y. Immobilizable fluorescent probes for monitoring the mitochondria microenvironment: a next step from the classic. Journal of Materials Chemistry B. 2019; 7: 2749-2758. 10.1039/c9tb00043g

44. Tang W, Fan W, Lau J, Deng L, Shen Z, Chen X. Emerging blood-brain-barrier-crossing nanotechnology for brain cancer theranostics. Chemical Society Reviews. 2019; 48: 2967-3014. $10.1039 /$ c8cs00805a

45. Ayo A, Laakkonen P. Peptide-Based Strategies for Targeted Tumor Treatment and Imaging. Pharmaceutics. 2021; 13: 481-512. 10.3390/pharmaceutics13040481

46. Zhao Z-Q, Yang Y, Fang W, Liu S. Comparison of biological properties of (99m)Tc-labeled cyclic RGD Peptide trimer and dimer useful as SPECT radiotracers for tumor imaging. Nuclear medicine and biology. 2016; 43: 661-669. 10.1016/j.nucmedbio.2016.02.006

47. Goel S, England CG, Chen F, Cai W. Positron emission tomography and nanotechnology: A dynamic duo for cancer theranostics. Advanced drug delivery reviews. 2017; 113: 157-176.

10.1016/j.addr.2016.08.001

48. Key J, Leary JF. Nanoparticles for multimodal in vivo imaging in nanomedicine. International journal of nanomedicine. 2014; 9: 711-726. 10.2147/ijn.s53717

49. Dong C, Yang S, Shi J, Zhao H, Zhong L, Liu Z, Jia B, Wang F. SPECT/NIRF Dual Modality Imaging for Detection of Intraperitoneal Colon Tumor with an Avidin/Biotin Pretargeting System. Scientific Reports. 2016; 6: 18905-18914. 10.1038/srep18905

50. Rangger C, Helbok A, Sosabowski J, Kremser C, Koehler G, Prassl R, Andreae F, Virgolini IJ, von Guggenberg E, Decristoforo C. Tumor targeting and imaging with dual-peptide conjugated multifunctional liposomal nanoparticles. International journal of nanomedicine. 2013; 8: 4659-4671. $10.2147 /$ ijn.s51927

51. Shi J, Kim YS, Chakraborty S, Zhou Y, Wang F, Liu S. Impact of bifunctional chelators on biological properties of 111 In-labeled cyclic peptide RGD dimers. Amino Acids. 2011; 41: 1059-1070. $10.1007 / \mathrm{s} 00726-009-0439-0$

\section{Figures}



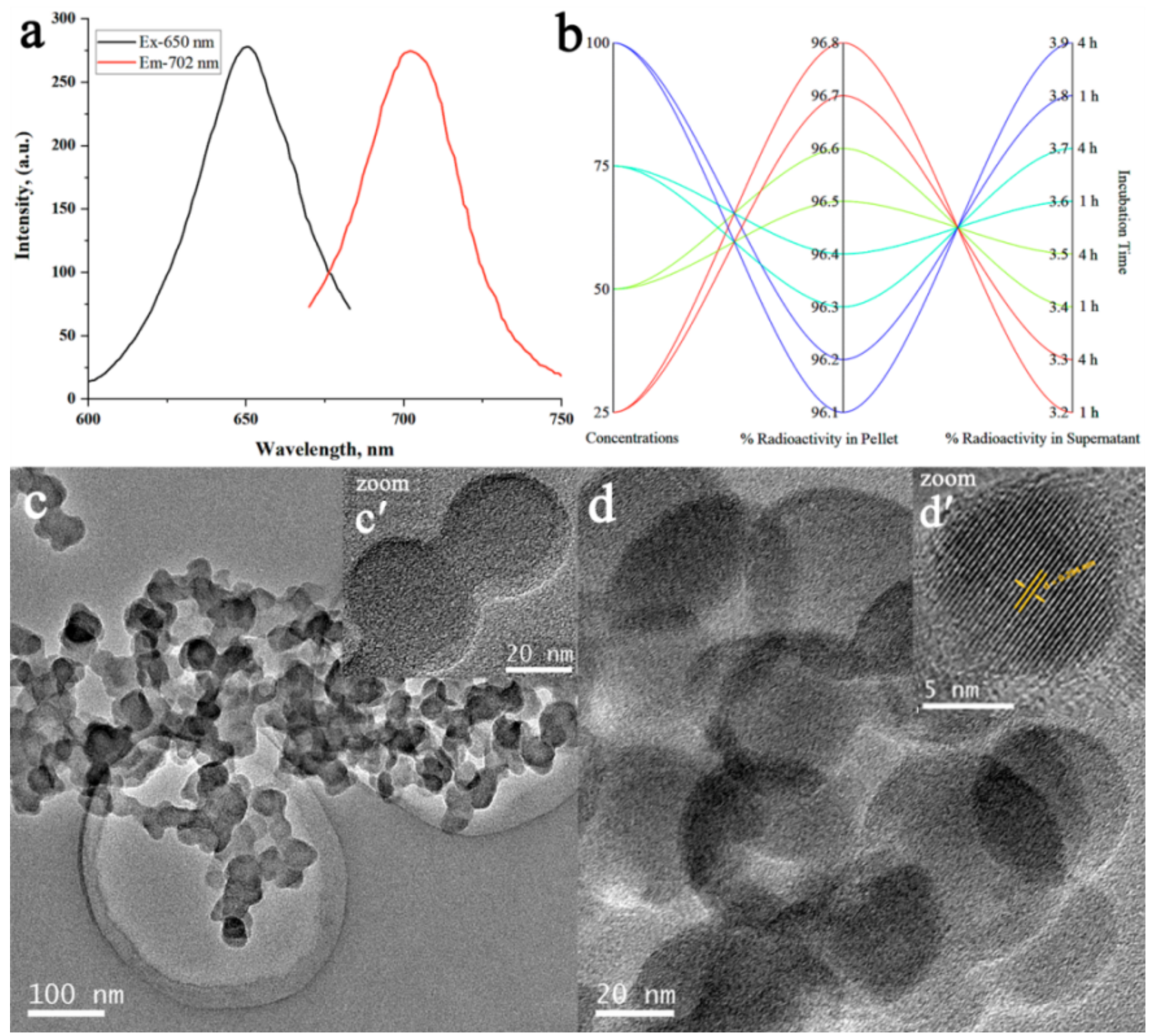

\section{Figure 1}

Qualitative analysis of Cy5.5@SAPD and Cy5.5@SAPD-99mTc nanoparticles, (a) shows fluorescence intensity measurement for Cy5.5@SAPD nanoparticles, (b) shows percent radiochemical yield of Cy5.5@SAPD-99mTc nanoparticles via ultracentrifugation, (c, d) shows TEM images acquired using dried Cy5.5@SAPD and Cy5.5@SAPD-99mTc nanoparticles; respectively. The inset figures show Highresolution TEM images of respective nanoparticles. 

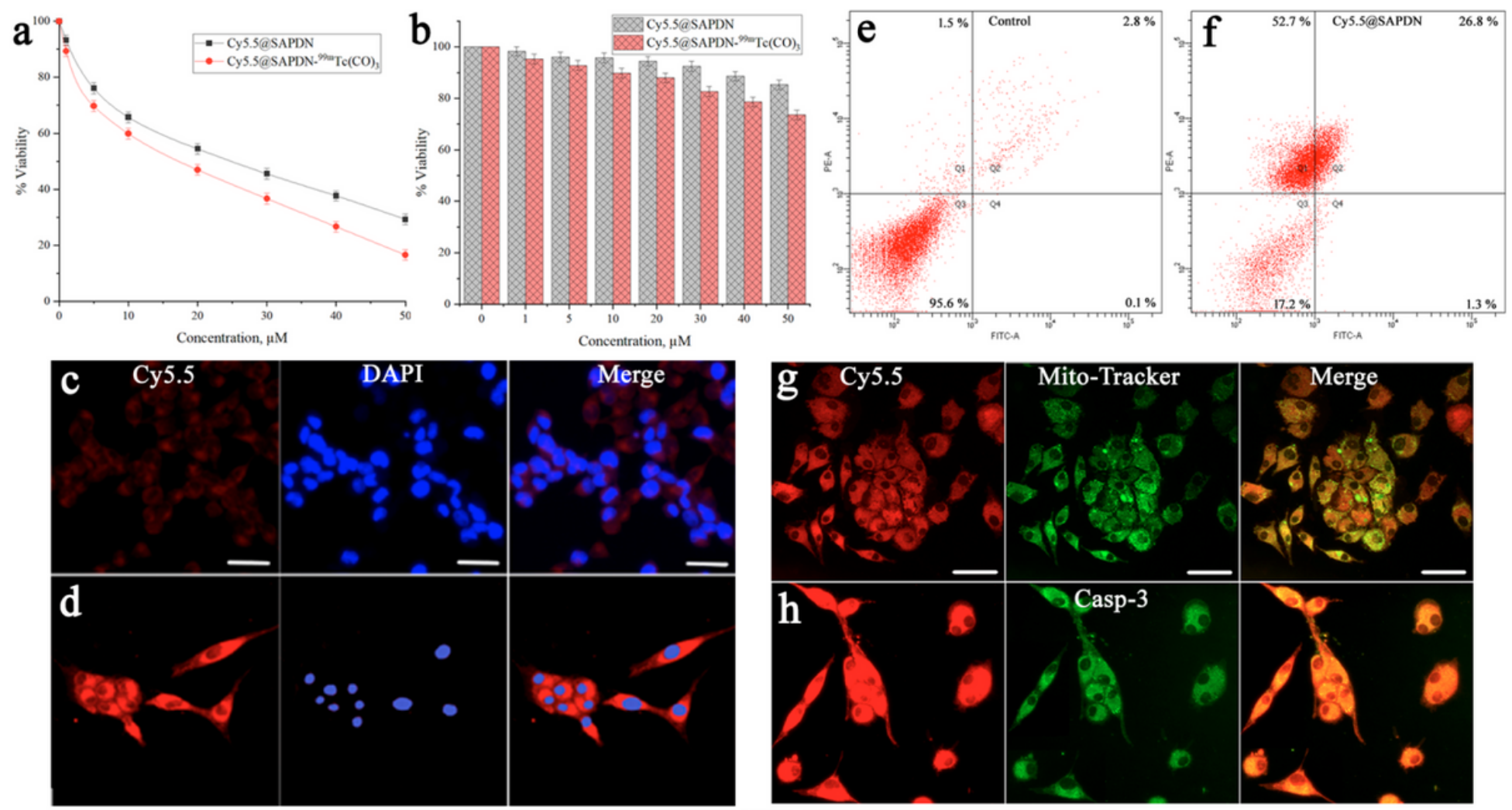

Mito-Tracker
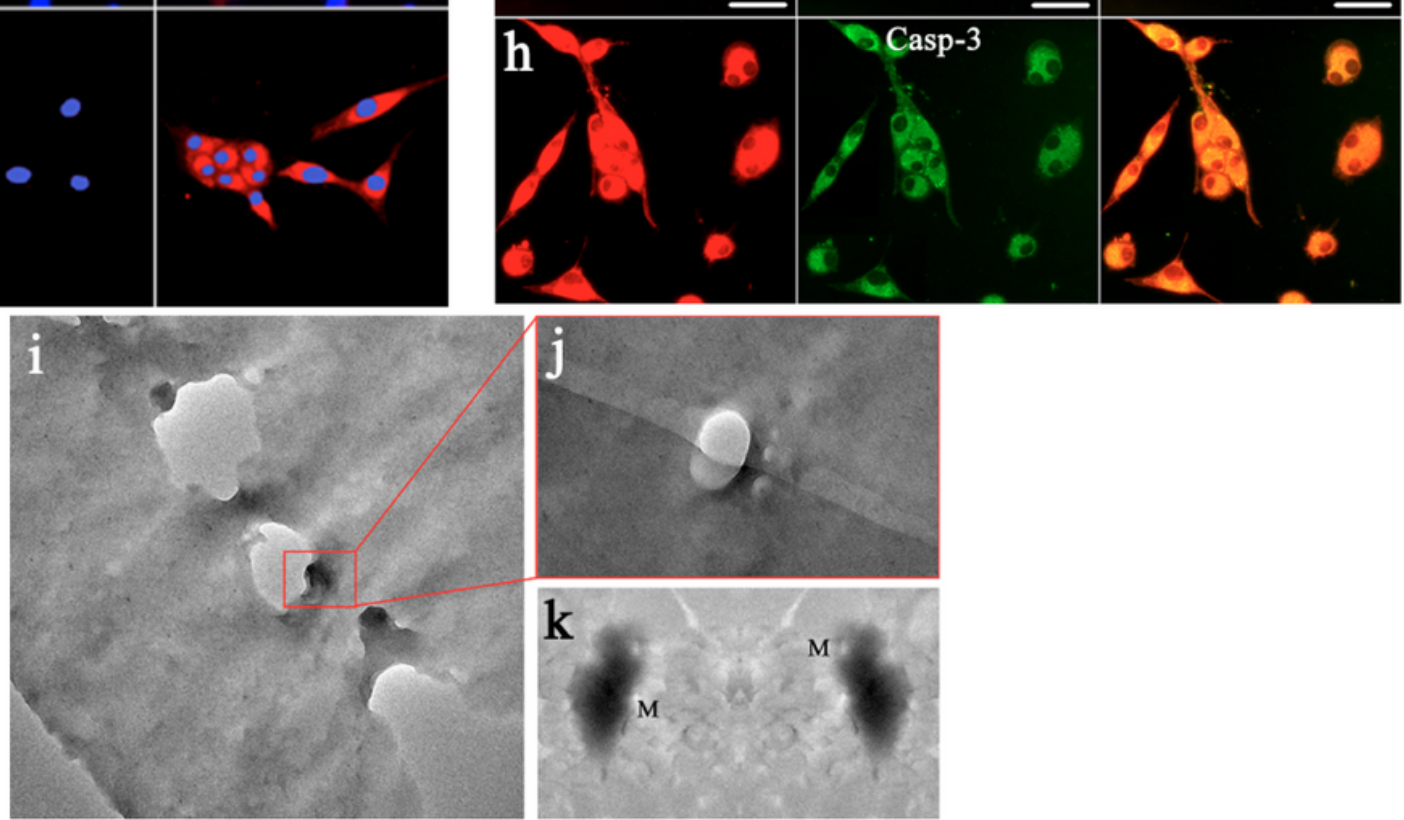

\section{Figure 2}

In vitro cell study of novel peptide nanoparticles using HEK-293 and U87MG glioblastoma cancer cell lines. Cytotoxicity study was performed in (a) U87MG cancer cell, and (b) HEK-293 cells using Cy5.5@SAPD and Cy5.5@SAPD-99mTc nanoparticles, (c, d) indicates CLSM images acquired with colocalization of Cy5.5@SAPD nanoparticles along with DAPI staining dye. FACS analysis shows apoptosis-inducing factor in U87MG cells (e) as control experiment and (f) for nanoparticles treated study, CLSM images acquired after co-localization of Mito-Tracker Green dye along with Cy5.5@SAPD nanoparticles ( $\mathrm{g}$ ) as well as caspase-3 staining dye (h). (i-k) shows bio-TEM images acquired after treatment with Cy5.5@SAPD nanoparticles in U87MG cells indicate successful mitochondrial damage. 


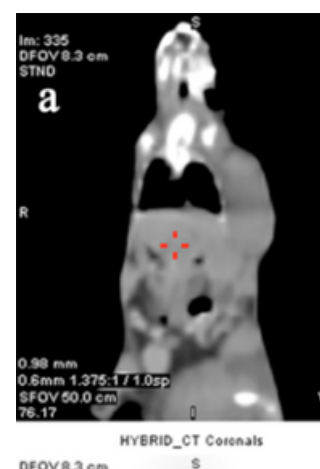

b

$\$$

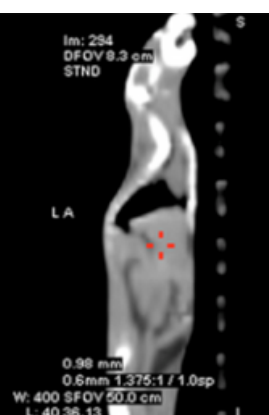

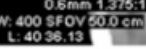

HVReid_CT Sagitals

OFOV $3 \mathrm{em}$ HYREID_CT S $\mathrm{s}$
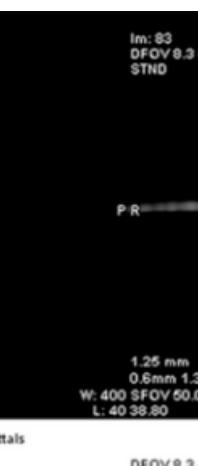

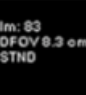
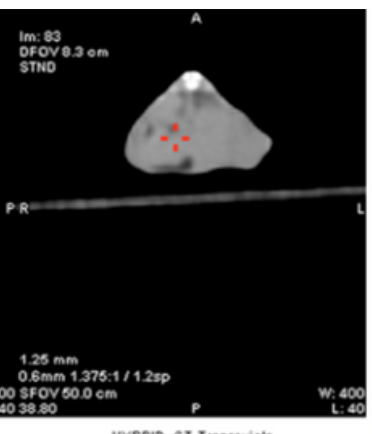

HYRerdeCT Transaxials

$\infty_{200}^{\infty}$

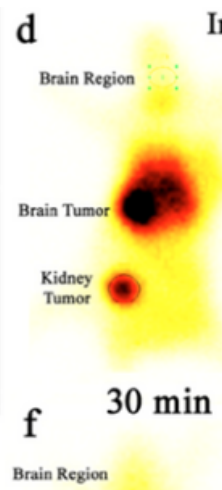

In vivo
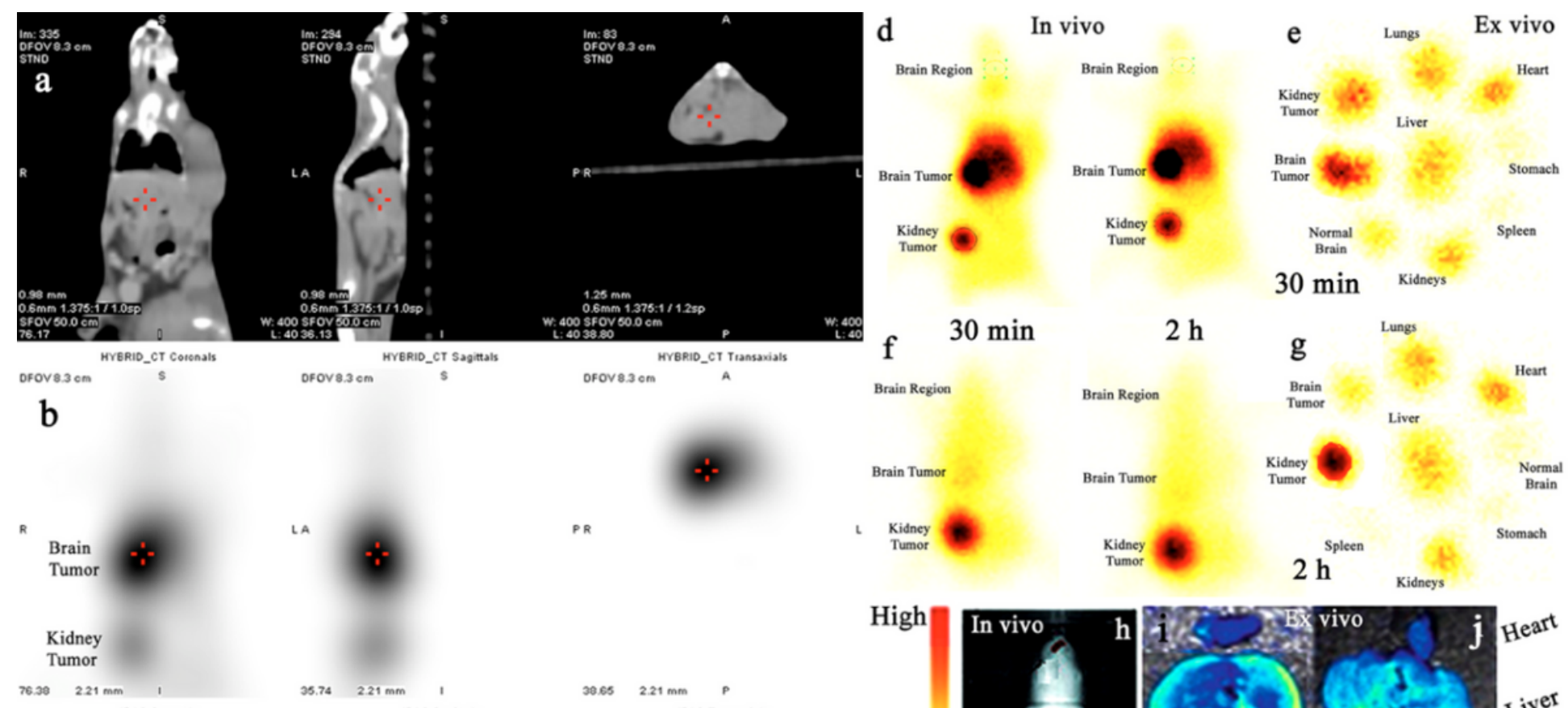

ofors.3
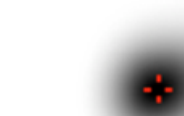

IRAC Coronals

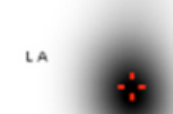

PR

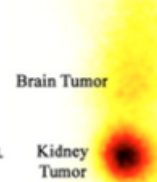

Brain Region

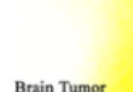

Brain Tumor

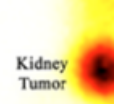

Kidney
Tumor
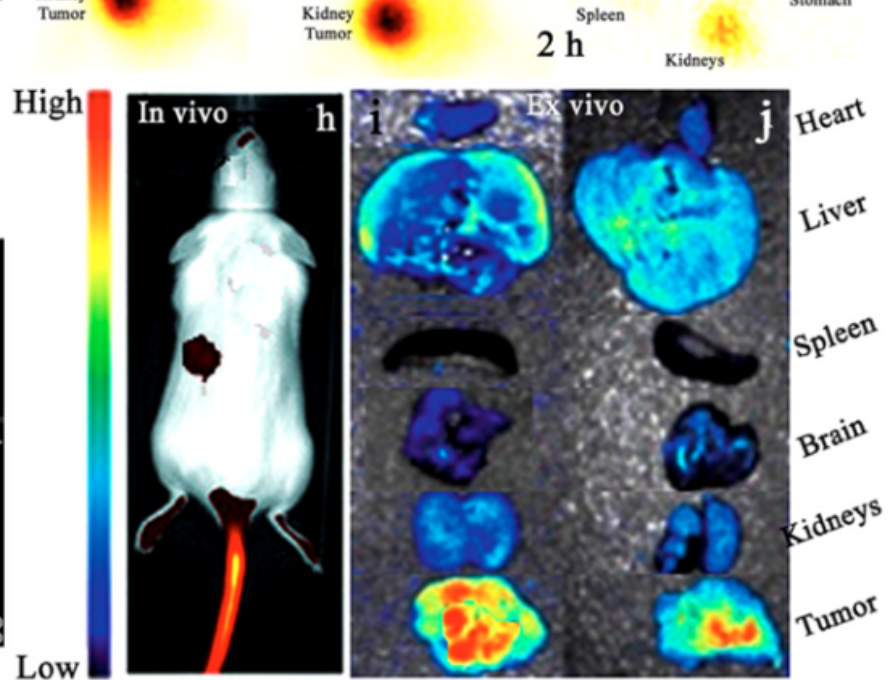

Figure 3

In vivo SPECT/ CT and fluorescence imaging studies in tumor-bearing animal models. (a-c) images show SPECT/ CT study of Cy5.5@SAPD-99mTc nanoparticles in brain tumor and kidney tumor-induced mice model, (d) shows in vivo static SPECT images after $30 \mathrm{~min}$ and $2 \mathrm{~h}$ post-injection (p.i) before therapeutic dose treatment (e) shows ex-vivo image indicating pharmacokinetic study, (f) shows SPECT images after $30 \mathrm{~min}$ and $2 \mathrm{~h} \mathrm{p}$.i after treatment, while (g) shows the ex-vivo image. (h) Indicates in vivo, (i) $30 \mathrm{~min}$ and (j) $2 \mathrm{~h}$ ex vivo fluorescence images in U87MG glioblastoma tumor-bearing mice model.

\section{Supplementary Files}

This is a list of supplementary files associated with this preprint. Click to download.

- Graphicalabstract.png

- schema1.png

- SupportingFile.docx 